BNL-NUREG-72136-2004-CP

\title{
An Assessment of Simplified vs. Detailed Methodologies for SSI Analyses of Deeply Embedded Structures
}

\author{
J. Xu ${ }^{1)}$, C. Miller ${ }^{1)}$, C. Hofmayer ${ }^{1)}$, H. Graves ${ }^{2)}$ \\ ${ }^{1)}$ Brookhaven National Laboratory, Upton, New York 11973-5000, USA \\ ${ }^{2)}$ U.S. Nuclear Regulatory Commission, Washington, D.C. 20555-0001, USA
}

\begin{abstract}
Sponsored by the US Nuclear Regulatory Commission (NRC), Brookhaven National Laboratory (BNL) is carrying out a research program to develop a technical basis to support the safety evaluation of deeply embedded and/or buried (DEB) structures as proposed for advanced reactor designs. In this program, the methods and computer programs established for the assessment of soil-structure interaction (SSI) effects for the current generation of light water reactors are evaluated to determine their applicability and adequacy in capturing the seismic behavior of DEB structures. This paper presents an assessment of the simplified vs. detailed methodologies for seismic analyses of DEB structures. In this assessment, a lump-mass beam model is used for the simplified approach and a finite element representation is employed for the detailed method. A typical containment structure embedded in a soil profile representative of a typical nuclear power plant site was utilized, considering various embedment depths from shallow to full burial. BNL used the CARES program for the simplified model and the SASSI2000 program for the detailed analyses. The calculated response spectra at the key locations of the DEB structure are used for the performance assessment of the applied methods for different depths of burial. Included in the paper are: 1) the description of both the simplified and detailed models for the SSI analyses of the DEB structure, 2) the comparison of the analysis results for the different depths of burial between the two methods, and 3) the performance assessment of the analysis methodologies for SSI analyses of DEB structures. The resulting assessment from this study has indicated that simplified methods may be capable of capturing the seismic response for much deeper embedded structures than would be normally allowed by the standard practice.
\end{abstract}

\section{INTRODUCTION}

Motivated by many design considerations, several conceptual designs for advanced reactors have proposed that the entire reactor building and a significant portion of the steam generator building will be partially or completely embedded below grade. For the seismic design and analysis of these types of deeply embedded structures, the soil-structure interaction (SSI) effect needs to be considered. It is understood that established SSI analysis computer codes used in the nuclear industry have been primarily developed for the current generation of Light Water Rectors (LWRs) and applied to coupled soil-structure models where the structures are founded at or near the ground surface with shallow embedment [Xu, et al., 2003]. Sponsored by the US Nuclear Regulatory Commission (NRC), Brookhaven National
Laboratory (BNL) is carrying out a multi-year research program to develop a technical basis to support the safety evaluation of deeply embedded and/or buried (DEB) structures as proposed for advanced reactor designs. In this program, the methods and computer programs established for the assessment of soil-structure interaction (SSI) effects for the current generation of light water reactors are evaluated to determine their applicability and adequacy in capturing the seismic behavior of DEB structures. This paper presents an assessment of the simplified vs. detailed methodologies for seismic analyses of DEB structures.

In this assessment, a lump-mass beam model is used for the simplified approach and a finite element representation is employed for the detailed method. A typical containment structure embedded in a soil profile representative of a typical nuclear power plant site was utilized, considering various embedment depths from shallow to full burial. BNL used the CARES program [Xu, et al., 1990 and Miller, et al., 2000] for the simplified model and the SASSI2000 program [Lysmer, et al., 1981 and 1999] for the detailed analyses. The BNL analyses are performed first to consider the kinematic effect, and then the full SSI effect. Due to limited space for this paper, only the SSI effect associated with acceleration time history is discussed. Other SSI effects such as seismic induced pressure and stress distributions in the structure are also expected to impact the seismic analysis methodologies for DEB structures, and will be discussed in future publications. In this paper, the seismic responses in terms of response spectra are calculated at the key locations of the DEB structure, which are used for the performance assessment of the applied methods for different depths of burial. Included in the paper are: 1) the description of both the simplified and detailed models for the SSI analyses of the DEB structure, 2) the comparison of the analysis results for the different depths of burial between the two methods, and 3) the performance assessment of the analysis methodologies for SSI analyses of DEB structures.

The paper is organized in four sections. Section 2 provides a description of the DEB structure used in the analysis, as well as the soil profile and an outcrop input motion. The analysis models using CARES and SASSI are described in Section 3. Section 4 provides a discussion on the comparison of the analysis results for the different depths of burial between the two methods, and the performance assessment of the analysis methodologies for SSI analyses of DEB structures. Finally, conclusions are drawn in Section 5. 


\section{CHARACTERISTICS OF DEB STRUCTURE AND SITE CONDITION}

A sketch of the DEB structure used in this study is shown in Figure 1, which is basically a cylindrical shell of reinforced concrete construction. The structure is derived from the characteristics of a conceptual design of a containment structure for advanced reactors. The cylinder is $46 \mathrm{~m}$ high and has an outer diameter of $27 \mathrm{~m}$. The actual containment consists of a variable thickness outer shell and several major walls spanning across the containment providing both flexural rigidity and dividing the space into major areas. This is modeled with a uniform thickness cylindrical shell. The wall thickness $(2 \mathrm{~m})$ is selected to match the combined moment of inertia of the actual outer shell and major interior dividing walls.

A major parameter varied in the study is the depth of burial (DOB) of this model. The model is buried to depths (E) equal to $25 \%(11.5 \mathrm{~m}), 50 \%(23 \mathrm{~m}), 75 \%(34.5 \mathrm{~m})$, and $100 \%$ (46m) of the structural height, which correspond to DOB to radius ratio $(\mathrm{E} / \mathrm{R})$ equal to $0.85,1.7,2.55$, and 3.4 respectively. Current technology has been limited to $E$ at the lowest end of this scale so that the primary objective of the study is to determine whether the application of this technology leads to uncertainties when the DOB increases beyond $25 \%$ of the facility height or $85 \%$ of the facility radius.

The stiffness characteristics of the internal equipment are not included in the model. However, the mass of the equipment is lumped with the mass of the cylindrical shell; the combined weight is $92,202 \mathrm{kN}$. The weights of the basemat and the roof are $40,474 \mathrm{kN}$ and $4,448 \mathrm{kN}$ respectively. The weights have been reduced to some extent from the actual weights to obtain structural frequencies that are likely to be interactive with the SSI frequencies. The following properties are used for the structure:

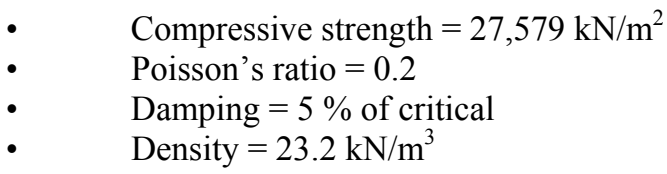

A layered soil site is considered, which is founded on bedrock at a depth of $80 \mathrm{~m}$. A shear wave velocity equal to 250 $\mathrm{m} / \mathrm{s}$ is assumed at the surface and $1,000 \mathrm{~m} / \mathrm{s}$ at a depth of 80 $\mathrm{m}$. Based on a relation between the low strain soil shear modulus and the confined soil pressure [Seed, et al., 1984], the variation of shear wave velocity for the soil between the surface and $80 \mathrm{~m}$ depth is determined:

$$
\mathrm{V}_{\mathrm{s}}=250+250.78 \mathrm{z}^{1 / 4}
$$

in which $\mathrm{z}$ is the depth of the soil column measured from ground surface. The soil profile is plotted in Figure 2, in which the discrete distribution is used in the current study. The other properties for the soil column are defined as: weight density $=$ $17.278 \mathrm{kN} / \mathrm{m}^{3}$, Poisson's ratio $=0.3$ and material damping equal to $4 \%$ of critical. The soil shear modulus and damping are not degraded as a function of shear strain in the soil column. In this way the level of the seismic input is not a parameter considered in the variation of parameter studies.

The input motion is specified at a rock outcrop and standard convolution procedures for vertically propagating horizontal shear waves are used to compute the free field motions within the soil column. The rock outcrop motion consistent with the Western US ground motion characteristics is developed according to the procedures specified in RG 1.165. The rock outcrop spectrum of the motion is shown on Figure 3.

\section{DESCRIPTION OF THE ANALYSIS MODELS}

As described in the introduction, the performance assessment of simplified vs. detailed methodologies is performed via comparisons of the DEB seismic responses computed with a lumped mass stick model and a finite element model. The CARES program is used to develop the lumped mass stick model, which is depicted in Figure 4. In this SSI model, the structure is represented with lumped masses and beams. The base of the model is connected to soil via interaction coefficients which include both base and side effects. Further, the embedded portion of the structure is assumed to be rigid and the method proposed by Iguchi [Iguchi, 1982], and further discussed by Pais, et al. [Pais, et al., 1985], is used to incorporate the kinematic interaction effect in the SSI model.

The detailed finite element model is developed using the SASSI 2000 program. The portion of the structure below the ground surface is modeled with explicit finite elements (e.g., 3-D bricks and shells), while the superstructure above the ground surface is represented with simple lumped masses and 3-D beams. A typical SASSI DEB model is shown in Figure 5. Due to the symmetric configuration of the structure, only half of the structure was modeled with the plane $y=0$ as the symmetry plane. As shown in this figure, the basemat was modeled with brick elements and the sidewalls and internals were modeled with shell elements. The base of the superstructure is connected to the sidewalls by rigid links to simulate the rigid diaphragm of the floor expected to exist at grade level. In order to apply the subtraction method as implemented in SASSI2000, the nodes at the boundary of the excavation need to be identified as the interaction nodes and the volume of the excavated pit was modeled.

\section{ASSESSMENT OF SIMPLIFIED vS. DETAILED METHODOLOGIES FOR DEB STRUCTURES}

In order to study the DEB effect on seismic analysis methodologies, seismic response analysis was performed using both CARES and SASSI models for various depths of embedment as discussed in Section 2. The analysis results using the two methods will then be compared to determine 
their performance with respect to the depth of burial for the structure. The response parameters used for the comparisons are response spectra at the center of the basemat and the center of the roof of the structure.

Figures 6 through 9 present comparisons of SASSI and CARES results in terms of response spectra for the depth of burial equal to $85 \%, 170 \%, 255 \%$, and $340 \%$ of the structural radius. As indicated in these figures, these comparisons show that in general, the frequency content for the major peak response are consistent between the two models, and the simplified method appears to produce higher peak response, except for the roof response for $\mathrm{E} / \mathrm{R}=0.85$, where SASSI produced much higher response than CARES (this is discussed further below). These figures also indicate that the simplified method could predict very reasonable seismic response for structures which are more deeply embedded than would be allowed according to standard practice.

To place the relative performance of the simplified vs. detailed methods in proper perspective, two other indicators were established for the assessment. The first indicator calculates the difference of the areas under the response spectra between CARES and SASSI results and plots it against a burial parameter expressed as the $E / R$ ratio (depth of burial/structural radius). This indicator provides an overall performance assessment across the entire frequency content. Since the seismic design is more interested in the peak response, a second indicator is constructed for the relative peak response difference. The peak responses compared are within the frequency range allowed by either peak shift or peak widening methods applied in the nuclear industry. The indicator is then plotted against the $E / R$ ratio. The first indicator for the depths of burial analyzed is shown in Figure 10. A clear trend of performance as function of the depth of burial is readily exhibited in this figure. This figure also indicates a close to uniform distribution of the responses (within $+/-10 \%$ difference) for the depth of burial up to $340 \%$ of structural radius. The only exception is the base response which CARES tends to under predict compared to SASSI; however, the under-prediction can be kept within $20 \%$ if the depth of burial is less than $300 \%$ of structural radius. To shed light on the extent to which kinematic interaction effects impact the performance assessment, Figure 11 provides a plot which includes only the kinematic interaction effect in the models.

To compliment the above assessment, the second indicator using peak response comparison is plotted in Figure 12. This indicator substantiates the observation made earlier on the comparisons of the results in terms of response spectra that CARES mostly produces higher peak response. Even for the under-predictions, CARES results are within $15 \%$ difference of the respective SASSI values for the full extent of the depth of burial analyzed. The only outlier is the point which represents the SSI roof response where CARES significantly under predicted the peak. The reason for this under prediction might be due to inadequate modeling of the aspect associated with inertial interaction, which appears to control the response for the shallow embedment case.

\section{CONCLUSIONS}

A study was performed to provide an assessment of simplified vs. detailed seismic analysis methodologies for DEB structures. A structure with the characteristics of a conceptual design of a containment structure for advanced reactors was modeled using the CARES program for the simplified method and the SASSI2000 program for the detailed model. A typical layered soil site was considered and a Western U.S. outcrop motion was used in the seismic analyses. The assessment of the methods was made first by examining the comparisons of the analysis results in terms of response spectra at key locations of the structure against various depths of embedment. Two performance indicators were subsequently established, one using the difference of the overall spectral areas computed with the two methods, and the other constructed to compare the relative peak spectral response difference. The two indicators together have proven to be a useful tool for performance assessment. The resulting assessment from this study has indicated that simplified methods may be capable of capturing the seismic response for much deeper embedded structures than would be normally allowed by the standard practice.

\section{DISCLAIMER NOTICE}

This work was performed under the auspices of the U.S. Nuclear Regulatory Commission, Washington, D.C. The findings and opinions expressed in this paper are those of the authors, and do not necessarily reflect the views of the U.S. Nuclear Regulatory Commission or Brookhaven National Laboratory.

\section{REFERENCES}

Iguchi, M., 1982, “An Approximate Analysis of Input Motions for Rigid Embedded Foundations," Trans. of Architectural Inst. of Japan, No. 315, pp. 61-75.

Lysmer, J., et al., 1999, "SASSI2000 - Theoretical Manual," Revision 1, Geotechnical Engineering, University of California, Berkeley.

Miller, C., et al., 2000, "CARES: Computer Analysis for Rapid Evaluation of Structures," Version 1.3, Earthquake Research Center at The City College of New York, prepared for U.S. Nuclear Regulatory Commission.

Pais, A., et al., 1985, "Stochastic response of foundations," Report No. R8506, MIT, Massachusetts.

Seed, H. B., et al., 1984, "Soil Moduli and Damping Factors for Dynamic Response Analysis of Cohesionless 
Soils,” Report No. UCB/EERC-8914, Earthq. Eng. Research Center, University of California, Berkeley, CA.

$\mathrm{Xu}$, J., et al., 2003, "Current Practice for Deeply Embedded/Buried NPP Structures Subject to Seismic Loadings," BNL Technical Report, prepared for the U.S.
Nuclear Regulatory Commission (NRC), Report No. Y-6718091603.

Xu, J., et al., 1990, "CARES (Computer Analysis for Rapid Evaluation of Structures), Seismic Module", Vol. 1, Theoretical Manual, Version 1.0, NUREG/CR-5588. 

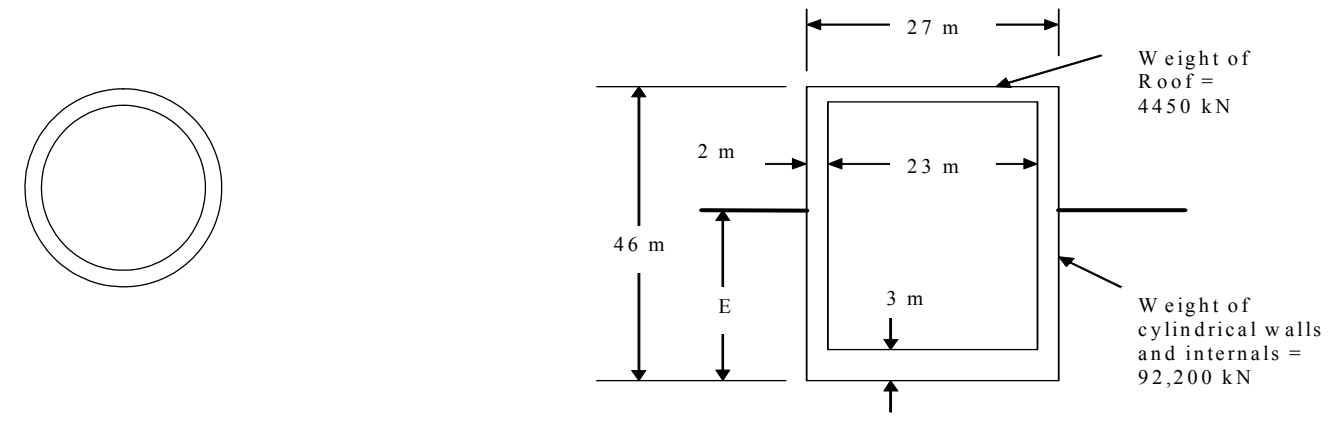

(a) Cross Section

(b) Elevation

Figure 1. Sketch of the Structure.

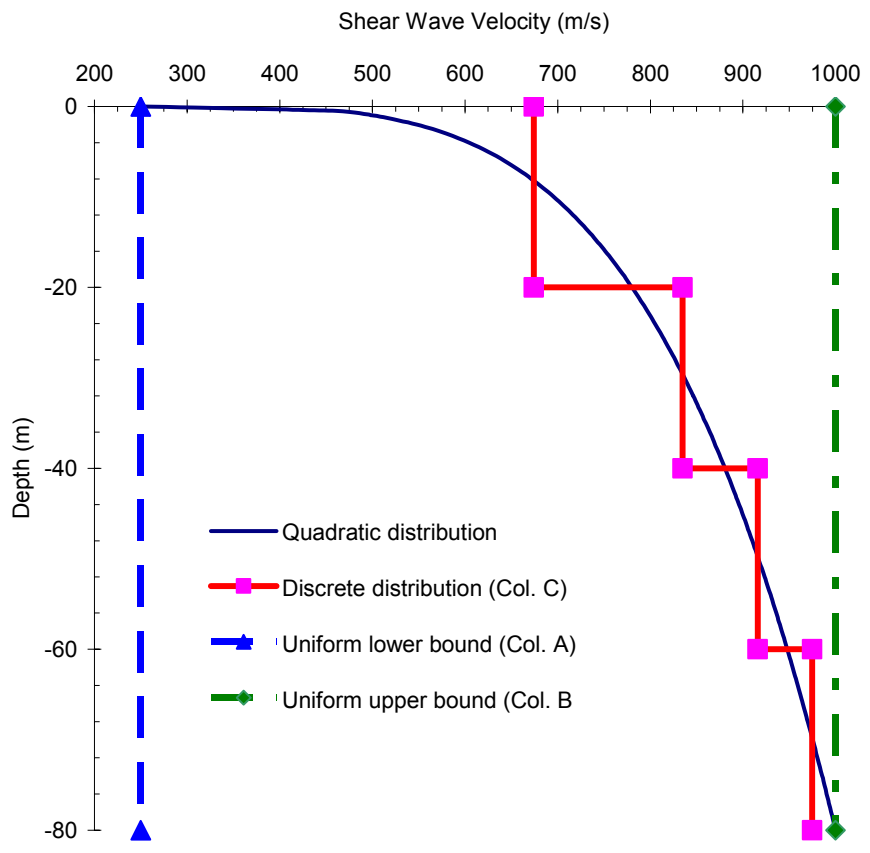

Figure 2. Site Soil Profile for SSI Analyses 


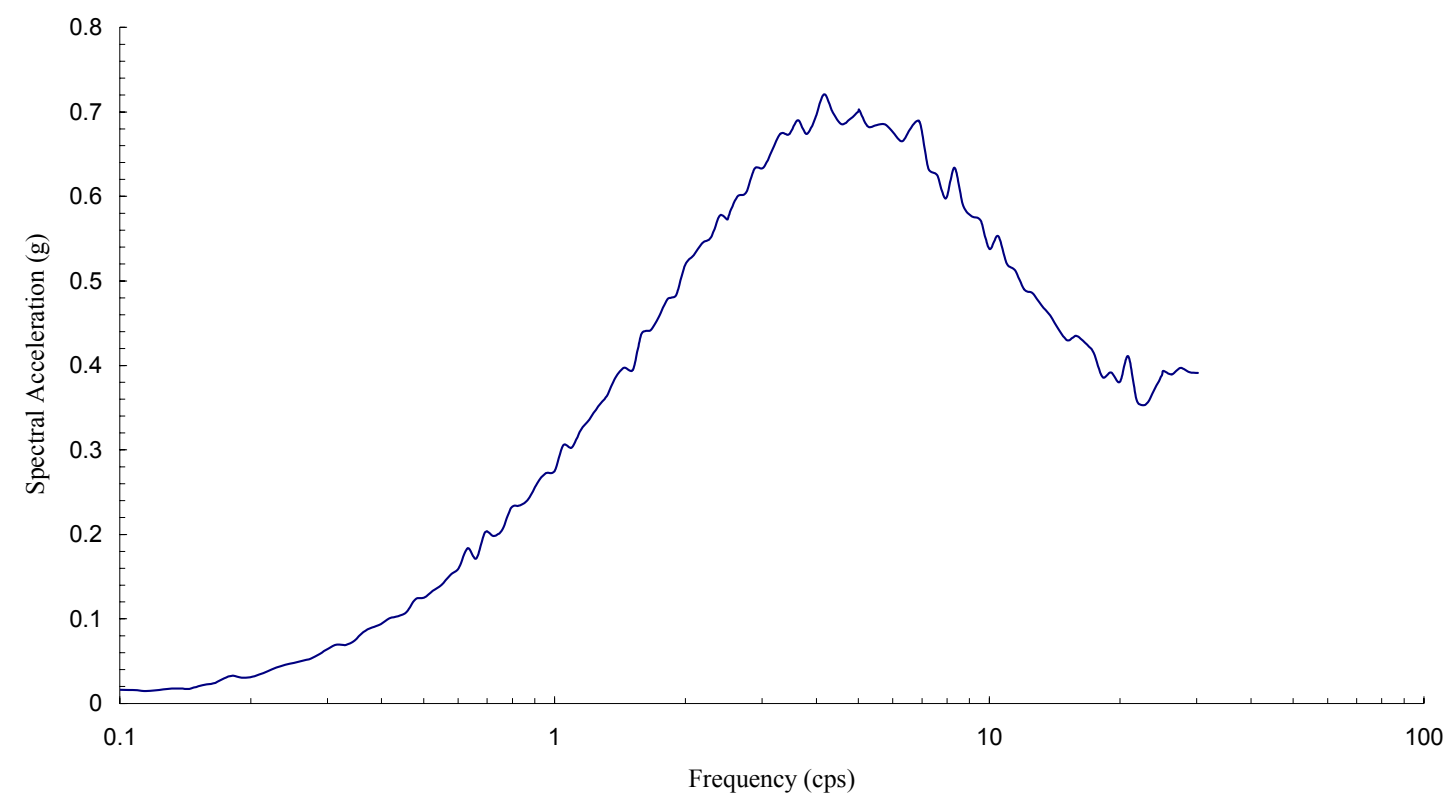

Figure 3. 5\% Damping Response Spectrum of Rock Outcrop Motion.

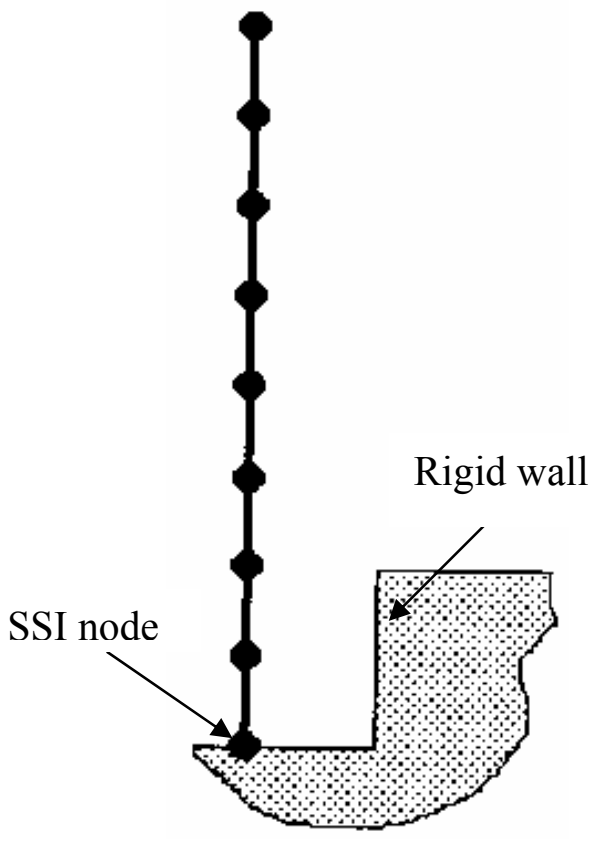

Figure 4. CARES Model.

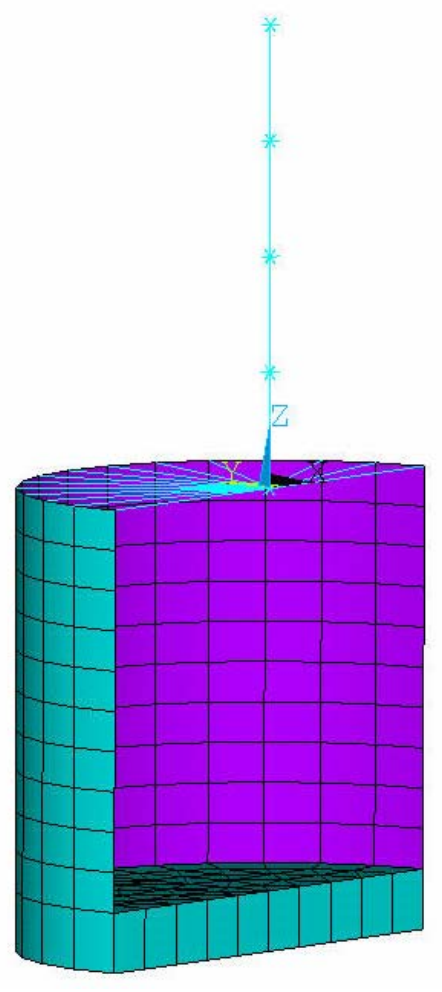

Figure 5. SASSI Model. 


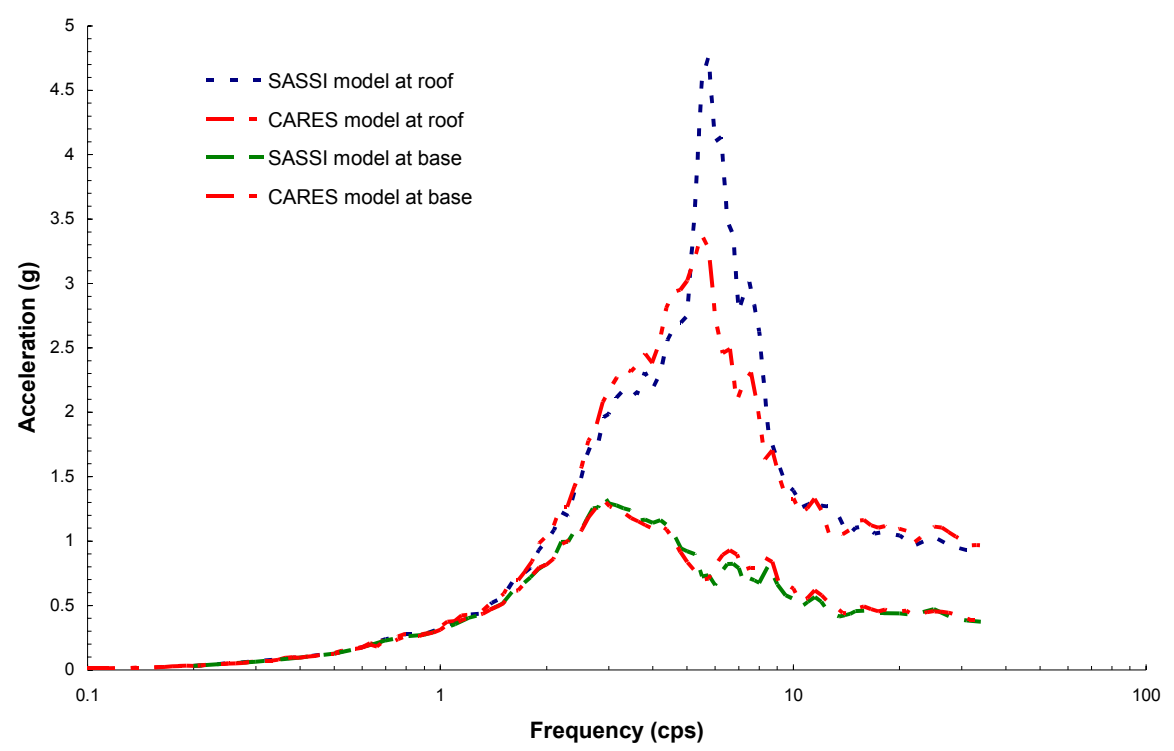

Figure 6. Comparisons of SSI Response Spectra for $\mathrm{E} / \mathrm{R}=0.85$.

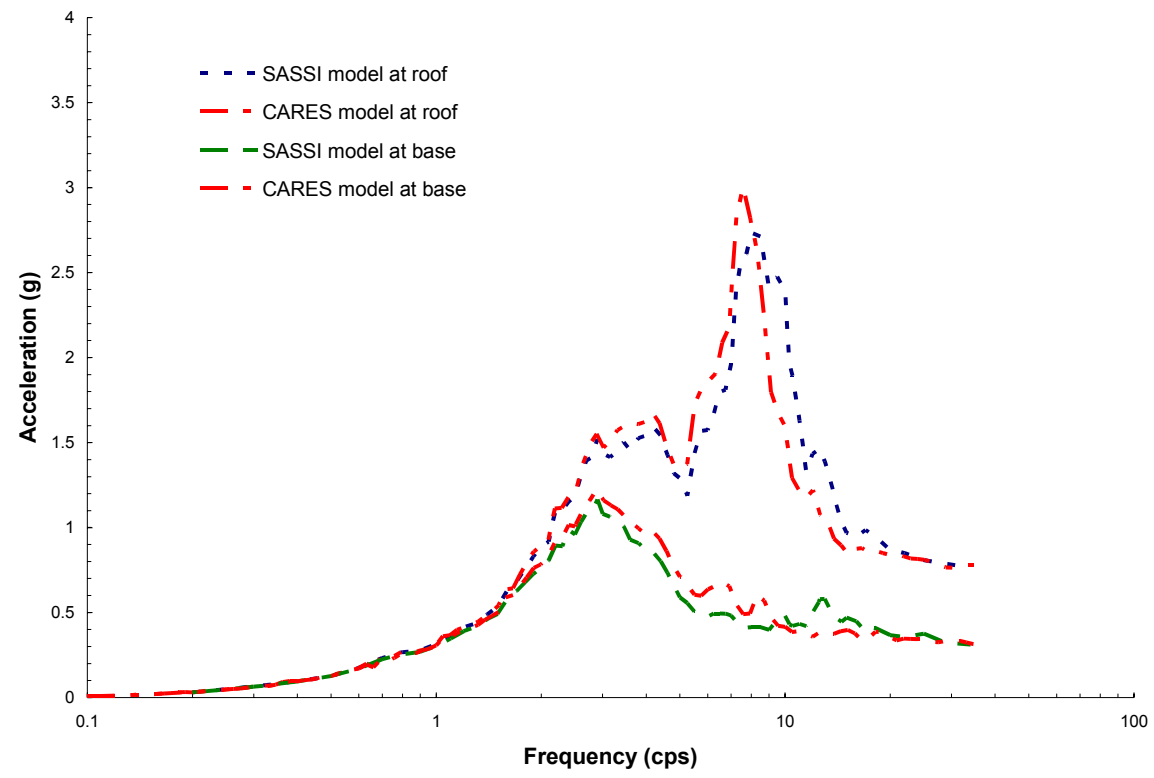

Figure 7. Comparisons of SSI Response Spectra for $E / R=1.7$. 


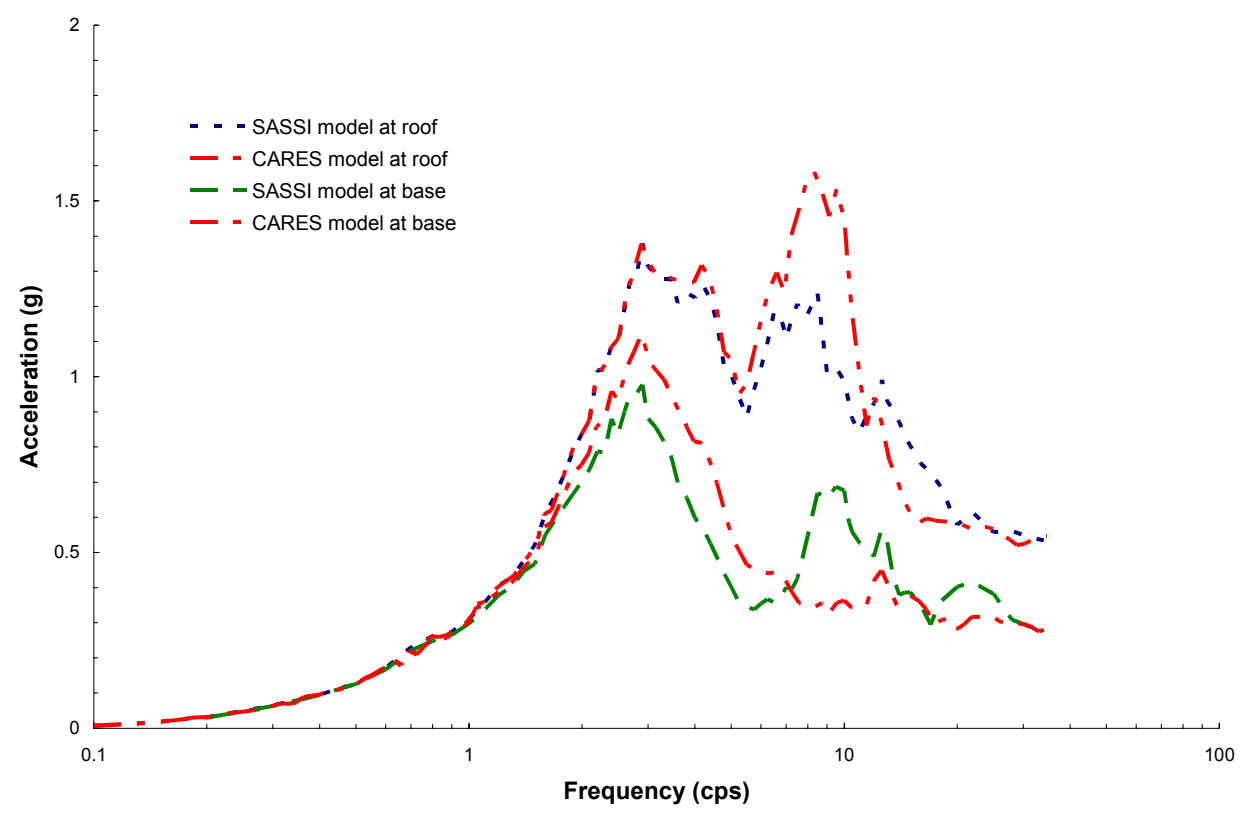

Figure 8. Comparisons of SSI Response Spectra for $E / R=2.55$.

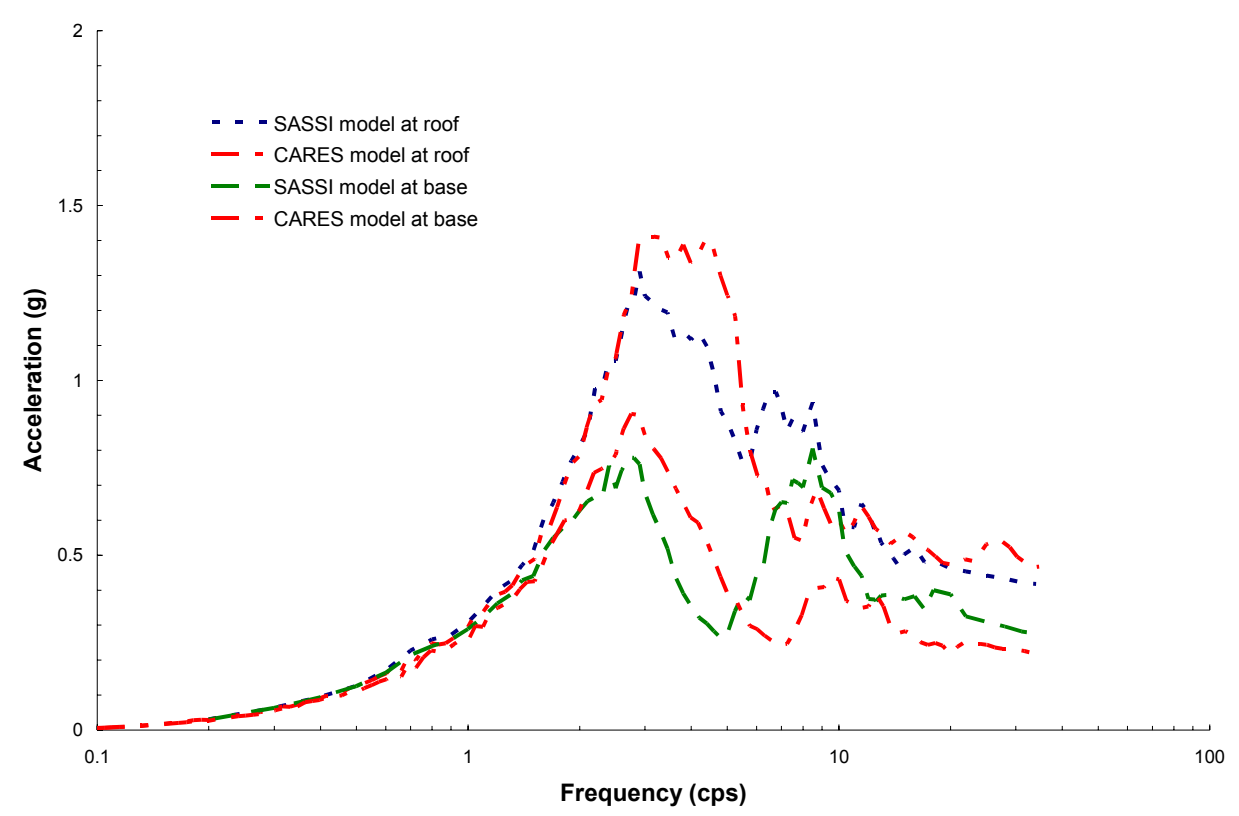

Figure 9. Comparisons of SSI Response Spectra for $E / R=3.4$. 


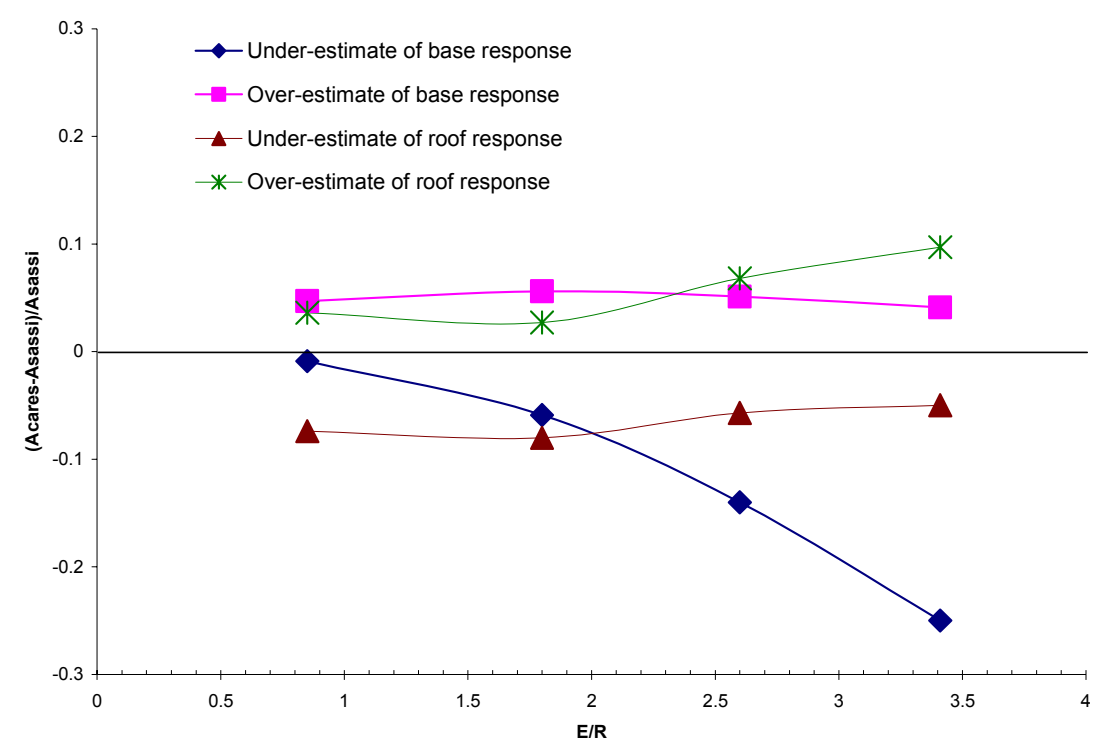

Figure 10. Assessment Using Spectral Area Difference between CARES and SASSI SSI Results.

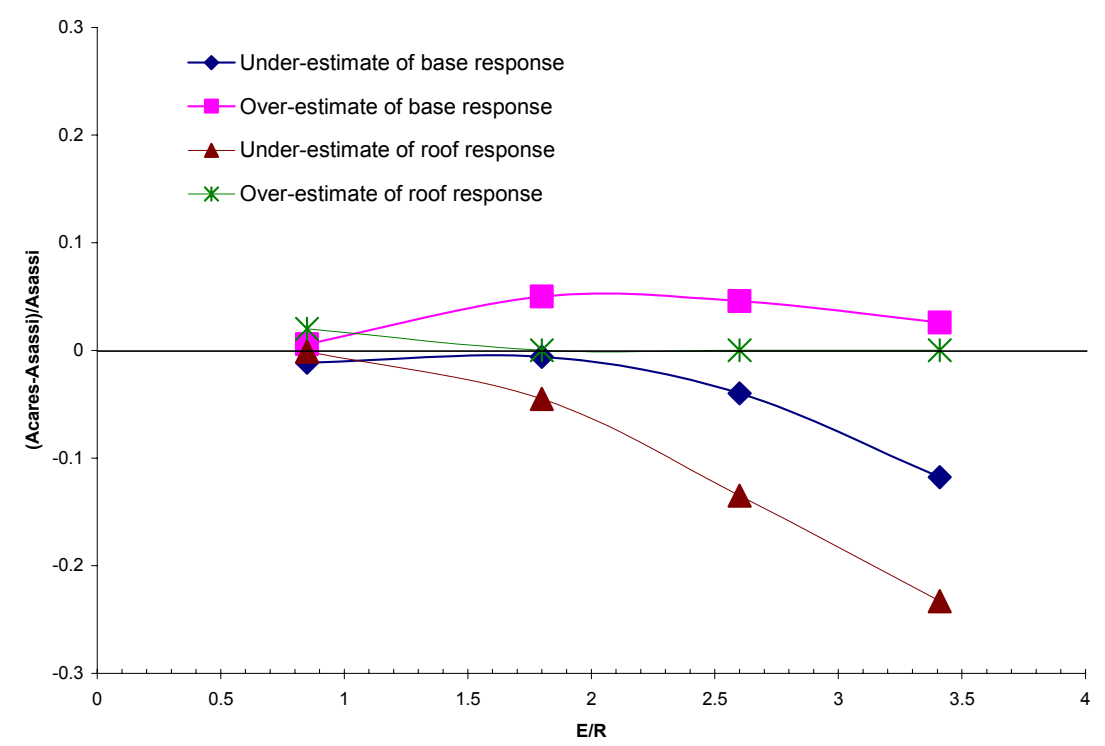

Figure 11. Assessment Using Spectral Area Difference between CARES and SASSI Kinematic Results. 


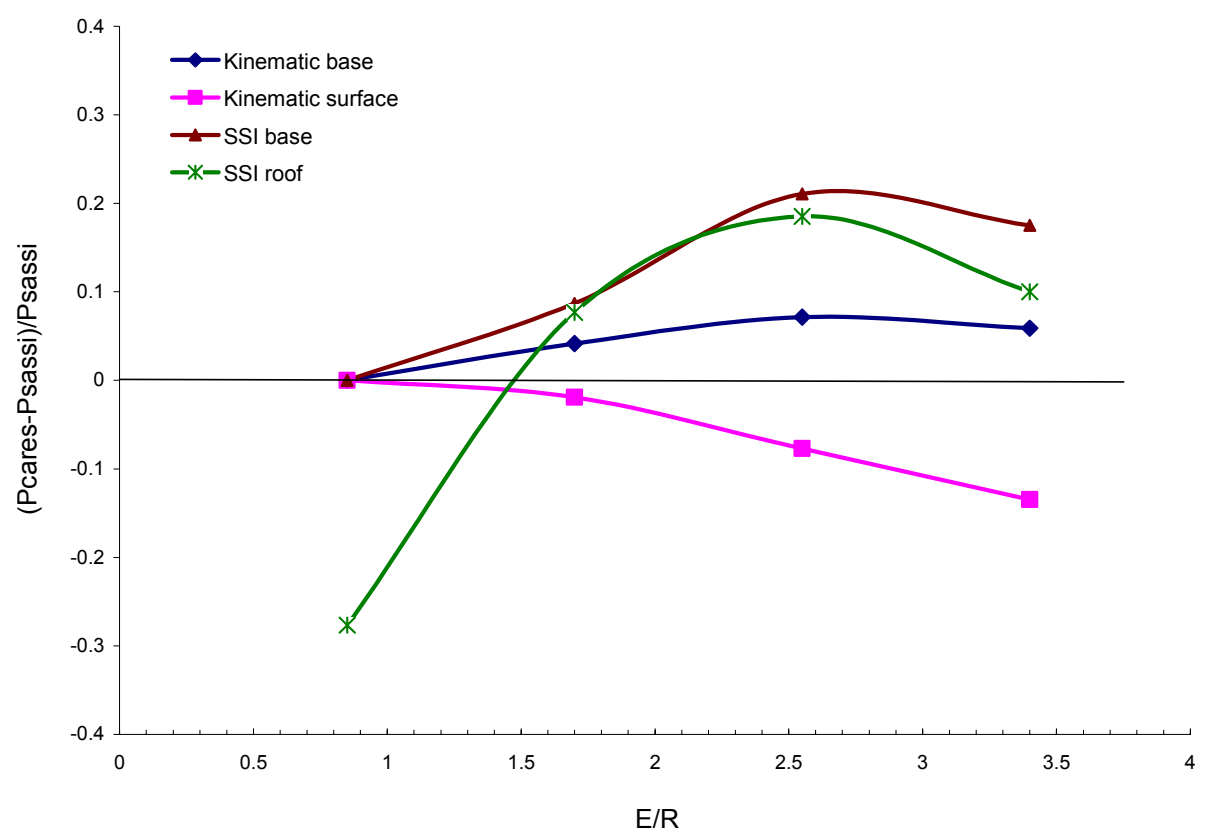

Figure 12. Assessment Using Spectral Peak Difference between CARES and SASSI Results. 